\title{
Effects of TIN2 on telomeres and chromosomes in the human gastric epithelial cell line GES-1
}

\author{
FAN FU $^{1,2^{*}}$, HUA HU $^{3 *}$, SHUAI YANG ${ }^{4}$ and XIAOQIU LIANG ${ }^{1}$ \\ ${ }^{1}$ Cancer Research Institute, Key Laboratory of Tumor Cellular and Molecular Pathology, College of Hunan, \\ University of South China, Hengyang, Hunan 421001; ${ }^{2}$ Department of Pathology, The Fourth Hospital of Changsha, \\ Changsha, Hunan 410006; ${ }^{3}$ Department of Pathology, The Second Affiliated Hospital; ${ }^{4}$ Department of Pathology, \\ The First Affiliated Hospital, University of South China, Hengyang, Hunan 421001, P.R. China
}

Received November 3, 2016; Accepted December 15, 2017

DOI: $10.3892 / 01.2018 .7927$

\begin{abstract}
TERF1-interacting nuclear factor 2 (TIN2) is a key member of the protein complexes that protect telomeres. TIN2 contributes an important role in biological processes. In a previous study by the present authors, an association was reported between high TIN2 protein expression and gastric cancer. Therefore, it was hypothesized that abnormal TIN2 expression may cause the development of malignancies, including, gastric carcinomas. To investigate this hypothesis, the present study employed peptide nucleic acid fluorescence in situ hybridization technology to analyze the human gastric epithelial GES-1 cells with high TIN2 expression or inhibited TIN2 expression. The results indicated that GES-1 cell lines with high TIN2 expression exhibited greater telomere dysfunction-induced damage compared with GES-1 cell lines with inhibited TIN2 expression. Chromosome analysis indicated that GES-1 cells with high TIN2 expression exhibited $2.48 \pm 1.30$ aberrant chromosomal changes per 100 cells, that may contribute to telomere DNA damage. Therefore, aberrant chromosomal alterations may provide a novel perspective for the pathogenesis of gastric cancer.
\end{abstract}

\section{Introduction}

Telomeres are special structures on the linear chromosome ends of eukaryotic cells and are masked with shelterin (1). Shelterin, a protective protein complex, consists of telomeric

Correspondence to: Professor Xiaoqiu Liang, Cancer Research Institute, Key Laboratory of Tumor Cellular and Molecular Pathology, College of Hunan, University of South China, 28 West Changsheng Road, Hengyang, Hunan 421001, P.R. China

E-mail: liangxiaoqiu368@163.com

*Contributed equally

Key words: TERF1-interacting nuclear factor 2, GES-1 cells, chromosome aberration, telomere dysfunction induced-foci repeat-binding factor (TRF)1, TRF2, tripeptidyl peptidase 1 (TPP1), TERF1-interacting nuclear factor 2 (TIN2), protection of telomeres 1 (POT1) and ras-related protein 1 (Rap1) (2). These proteins maintain telomere integrity and protect chromosomes (3). TIN2 is a core part of this system of protective proteins.

TIN2 is a crucial telomere-associated protein that interacts with telomeric double-stranded DNA and TRF1 and 2 binding proteins (4). TPP1 performs its role in the shelterin complex by interacting with TIN2, which directly combines and interacts with TPP1 (5). In human cells, the interactions between TIN2 and TPP1 have a major role in the recruitment of telomerase to the telomere. These interactions between TIN2 and TPP1 are independent, and are independent of the interactions between POT1 and shelterin on a single strand region of the telomere $(6,7)$. In dyskeratosis congenita, more serious symptoms are associated with mutant TIN2 genes compared with normal TIN2 genes (8). Therefore, TIN2 has become the focus of research.

Bhanot and Smith (9) and Frescas and de Lange (10) reported that the depletion of TIN2 alters other shelterin-associated proteins, including, TRF1, TRF2 and POT 1, thereby resulting in chromosomal instability. Previous studies on shelterin have been reported, where high expression levels of TRF1 and TRF2 mRNA have been observed in lung (11), liver $(12,13)$ and gastric cancer $(14)$ as well as lymphoma (15). However, low levels of TRF1 and TRF2 mRNA expression have also been observed in breast (16) and gastric cancer (17). Therefore, it was hypothesized that high or low protein expression may induce instability of shelterin, which may lead to the occurrence of malignant tumors. In a previous study by the present authors, it was detected that TIN2 protein expression was higher in the precancerous lesion, gastric cancer and metastasis groups compared with the normal group (18). Furthermore, the expression of TIN2 protein was higher in the gastric cancer and metastasis groups compared with the precancerous group (18). Therefore, it was hypothesized that abnormal TIN2 expression may induce shelterin instability, thereby leading to the occurrence of malignant tumors.

In the present study, peptide nucleic acid fluorescent in situ hybridization (PNA-FISH) and chromosome analysis were utilized to analyze the human gastric epithelial cell 
line, GES-1, with overexpressed or inhibited TIN2 expression. The results from the present study demonstrated that TIN2 overexpression by GES-1 cells resulted in increased telomere dysfunction-induced damage and increased the number of aberrant chromosomal alterations. To the best of our knowledge, the present study is the first to report on the association between gastric cancer and TIN2. This association may provide a novel perspective for the pathogenesis of gastric cancer.

\section{Materials and methods}

Cell culture. Human gastric epithelial GES-1 cells (Shanghai Innovation Biotechnology Co., Ltd., Shanghai, China) and transfected cells were cultured in Dulbecco's modified Eagle's medium (HyClone; GE Healthcare, Chicago, IL, USA) complete medium supplemented with $10 \%$ fetal bovine serum (FBS; Gibco; Thermo Fisher Scientific, Inc., Waltham, MA, USA). The cells were maintained in a humidified incubator with $5 \% \mathrm{CO}_{2}$ at $37^{\circ} \mathrm{C}$.

Establishment of human gastric epithelial GES-1 cell lines with overexpressed or inhibited TIN2 expression. A total of $2 \times 10^{5}$ cells/well GES-1 cells were transfected with $8 \mu$ l GES-1-GTP-hTIN2 (with $400 \mu 1$ 10\% FBS), GES-1-hTIN2-short hairpin RNA (SH)1, GES-1-hTIN2-SH2, GES-1-hTIN2-SH3 (target gene was TIN2; sequence, 5'-GCAGGAACTTGAACAAGAGTA-3' synthesized by Shanghai Innovation Biotechnology) in a lentivirus vector constructed by Shanghai Innovation Biotechnology, (Shanghai, China) and $6 \mu \mathrm{l}$ control lentivirus in 24-well plates. The medium was replaced at $8 \mathrm{~h}$ post-transfection. The cells were observed by inverted fluorescence microscopy $96 \mathrm{~h}$ after transfection. The GES-1 cells with stable TIN2 overexpression or inhibited TIN2 expression and their corresponding control cell lines were screened by the addition of puromycin $(0-15 \mu \mathrm{g} / \mathrm{ml})$.

Detection of TIN2 with reverse transcription-quantitative polymerase chain reaction (RT-qPCR). TIN2 gene expression was examined by RT-qPCR. Total RNA was extracted from GES-1 cells using a RNA extraction kit (cat no. K08MG; Omega Bio-Tek, Inc., Norcross, GA, USA), according to the manufacturer's protocol (Takara Biotechnology Co., Ltd., Dalian, China). Total cell RNA was reverse transcribed to cDNA (cat no. K1622; Thermo Fisher Scientific, Inc.), according to the manufacturer's protocol. The cDNA of normal GES-1 cells, GES-1 cells overexpressing TIN2, and GES-1 cells with inhibited TIN2 expression was subjected to qPCR (QuantiFast ${ }^{\mathrm{TM}} \mathrm{SYBR}^{\mathrm{R}}$ Green PCR kit; Qiagen GmbH, Hilden, Germany). The Real-time PCR cycling machine was purchased from Applied Biosystems, Thermo Fisher Scientific, Inc. The thermocycling conditions were as follows: Predenaturation for $2 \mathrm{~min}$ at $93^{\circ} \mathrm{C}$, then at $93^{\circ} \mathrm{C}$ for $1 \mathrm{~min}$, $55^{\circ} \mathrm{C}$ for $1 \mathrm{~min}, 72^{\circ} \mathrm{C}$ for $1 \mathrm{~min}$ and extension for $7 \mathrm{~min}$ at $72^{\circ} \mathrm{C}$ for 40 cycles. The reference gene used was GAPDH, and the experiment was repeated three times. The primer sequences used were as follows: GAPDH forward, 5'-GGAGTCCAC TGGCGTCTTC-3'; and reverse, 5'-GCTGATGATCTTGAG GCTGTTG-3'. The TIN2 primer sequences were as follows:
Forward, 5'-AAGTCC TGA A AGCCC TGA ATC AC-3'; and reverse 5'-GGTTCCCCATACTCTTGTTCAAGTT-3'. The formula $2^{-\Delta \Delta \mathrm{Cq}}$ was used to calculate the relative expression of the target gene (19).

Analysis of TIN2 protein expression by western blotting. TIN2 protein expression was examined by western blotting. The cells in the flasks were washed with refrigerated phosphate-buffered saline (PBS) three times. Then, $100 \mu \mathrm{l}$ cell lysate was added to the cells. Following lysis for $30 \mathrm{~min}$ on ice, the cells were scraped off the flasks. The cells were centrifuged at $14,000 \mathrm{x}$ g for $15 \mathrm{~min}$ at $4^{\circ} \mathrm{C}$. Protein concentration in the supernatant was detected by bicinchoninic acid assay. Each well contained $30 \mu \mathrm{g}$ of protein. To denature protein, $4 \mathrm{X}$ loading buffer was added to each well. The samples were then heated to $100^{\circ} \mathrm{C}$ for $5 \mathrm{~min}$. SDS-PAGE was performed on $10 \%$ gel, and the proteins bands were transferred to a polyvinylidene difluoride membrane. Blocking was performed in TBST containing 5\% skimmed milk for $2 \mathrm{~h}$ at $37^{\circ} \mathrm{C}$. The membrane was incubated a TIN2 primary antibody (dilution, 1:1,000; cat no. ab13791; Abcam, Cambridge, UK.) overnight at $4^{\circ} \mathrm{C}$. The membrane was then washed with TBST 3 times for $15 \mathrm{~min}$. The membrane was incubated with the corresponding horseradish peroxidase-conjugated goat anti-rabbit secondary antibodies (dilution, 1:3,000; cat no. CW0156S; Bejing Comwin Biotechnology, Co., Ltd., Beijing, China) for $1 \mathrm{~h}$ at room temperature and then washed three times with TBST for 15 min each time. Protein detection was performed using an enhanced chemiluminescence system, and images of the blots were analyzed by BioRad system (Bio-Rad Laboratories, Inc., Hercules, CA, USA). The experiment was repeated three times.

PNA-FISH analysis. The cells were fixed onto microscope slides. The cells were washed with PBS three times and then fixed in $4 \%$ paraformaldehyde for $15 \mathrm{~min}$ at $37^{\circ} \mathrm{C}$. The cells were permeabilized with $0.5 \%$ Triton X-100 (Solarbio Science and Technology, Co., Ltd, Beijing, China) for $20 \mathrm{~min}$ and washed with PBS three times. The slides were placed in $4 \%$ bovine serum albumin (Gibco; Thermo Fisher Scientific, Inc.), blocking buffer $(70 \%$ formamide; $0.5 \%$ blocking reagent; Tris- $\mathrm{HCl}, \mathrm{pH}$ 7.2) for $2 \mathrm{~h}$ at $37^{\circ} \mathrm{C}$. The slides were incubated at $37^{\circ} \mathrm{C}$ with rabbit antibody against $\mathrm{H} 2 \mathrm{AX}$ (dilution, 1:1,000; cat no. 9718; Cell Signaling Technology, Inc., Danvers, MA, USA) in a humidified chamber overnight. The film was incubated at $37^{\circ} \mathrm{C}$ with goat anti-mouse $\mathrm{IgG}$ secondary antibodies (dilution, 1:5,000; cat no. 5257; Cell Signaling Technology, Inc.) for $1 \mathrm{~h}$ and then washed three times with PBS. PNA probes (cat no. F1002; Panagene Inc., Daejeon, Republic of Korea) were joined on each climbing flake and then denatured at $80^{\circ} \mathrm{C}$ for $10 \mathrm{~min}$. The cells were incubated for $2 \mathrm{~h}$ at $37^{\circ} \mathrm{C}$, and then washed with Tris- $\mathrm{HCl}(\mathrm{pH} 7.2)$ and $70 \%$ formamide. The fixed cells were sequentially dehydrated in 70, 95 and $100 \%$ ethanol at $5 \mathrm{~min}$ for each step. The cells were observed under a fluorescence microscope following DAPI staining at $37^{\circ} \mathrm{C}$ for $30 \mathrm{sec}$. A total of 500 cells were analyzed for each group.

Chromosome preparation. A total of $1 \mu 1$ colchicine $(0.2-0.4 \mathrm{mg} / \mathrm{ml})$ was added to the cells in culture bottles. The cells were incubated for $2 \mathrm{~h}$ and then digested with trypsin 

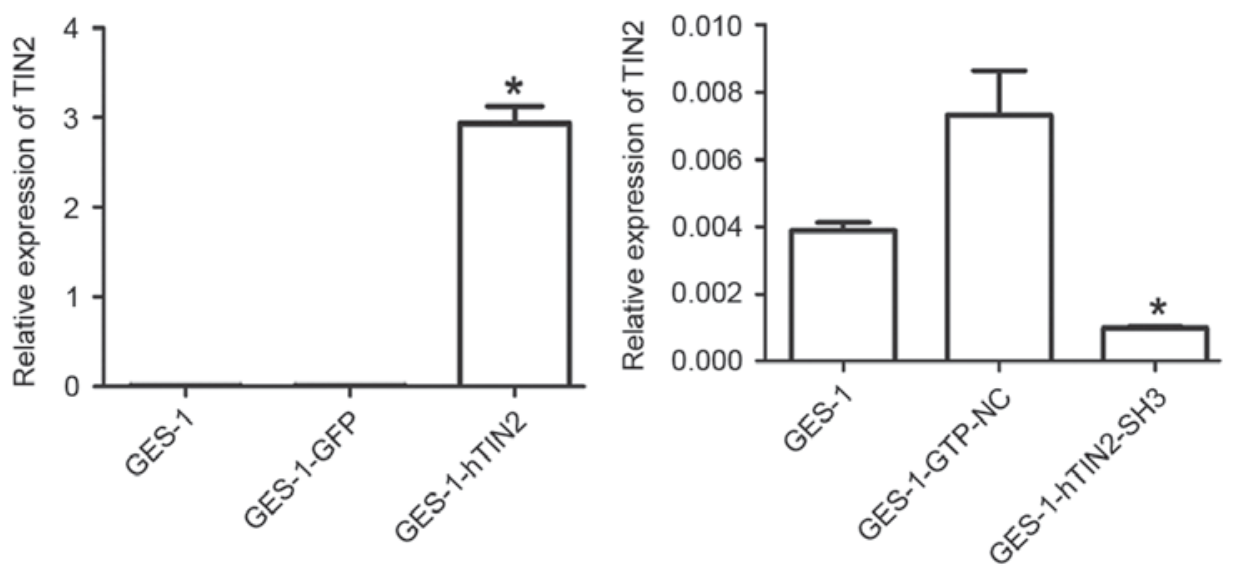

Figure 1. Relative expression levels of TIN2 in GES-1 and corresponding transfected cell lines. ${ }^{*} \mathrm{P}<0.05$ vs. GES-1 cells. GES-1, normal human gastric epithelial cell line; GES-1-GFP, TIN2 overexpression vector group; GES-1-hTIN2, TIN2 overexpression group; GES-1-GTP-NC, low TIN2 expression vector group; GES-1-hTIN2-SH3, inhibited TIN2 expression group; TIN2, TERF1-interacting nuclear factor 2.

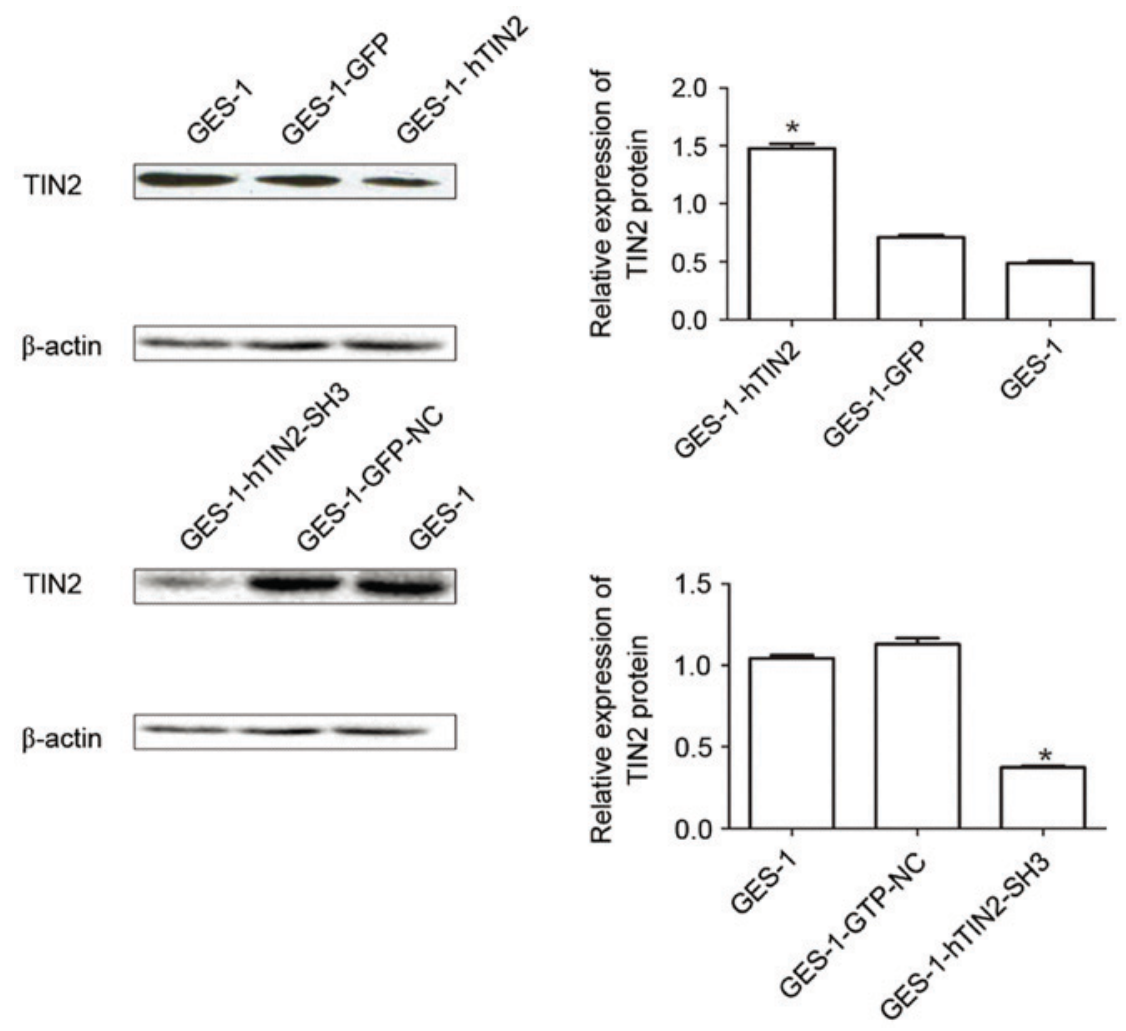

Figure 2. Detection of TIN2 protein expression in GES-1 and corresponding transfected cells lines by western blotting. "P<0.05 vs. GES-1 cells. GES-1-hTIN2-SH3, inhibited TIN2 expression group; GES-1-GTP-NC, low TIN2 expression vector group; NC, negative control; TIN2, TERF1-interacting nuclear factor 2 .

(cat no. A600322; Sangon Biotech, Co., Ltd., Shanghai, China). The supernatant was discarded after the cells were centrifuged at $200 \mathrm{x}$ g for $5 \mathrm{~min}$ at $37^{\circ} \mathrm{C}$. $\mathrm{KCl}(0.075 \mathrm{~mol} / \mathrm{l})$ was added to the cells, and the cells were incubated at $37^{\circ} \mathrm{C}$ for $20 \mathrm{~min}$. Then, $1 \mathrm{ml}$ chromosome fixative (methanol: Acetic acid, 3:1) was added to the cells. The cells were centrifuged at $400 \mathrm{x} \mathrm{g}$ for $10 \mathrm{~min}$ 5257; Cell Signaling Technology at $37^{\circ} \mathrm{C}$. The addition of chromosome fixative and the centrifugation step was repeated. A chromosome fixative was added drop-wise to prepared slides. Finally, the chromosomes were observed by $10 \%$ Wright-Giemsa staining for $10 \mathrm{~min}$ at $37^{\circ} \mathrm{C}$.
The chromosomal aberrations of 100 cells per group were recorded.

Statistical analysis. The data are presented as the mean \pm standard deviation. Experimental data were analyzed using SPSS statistical software (version 18.0; SPSS, Inc., Chicago, IL, USA). The significance of the group difference was evaluated by single-factor analysis of variance (ANOVA). Multiple comparisons between the groups were performed using Student-Newman-Keuls method. $\mathrm{P}<0.05$ was considered to indicate a statistically significant difference. 
A

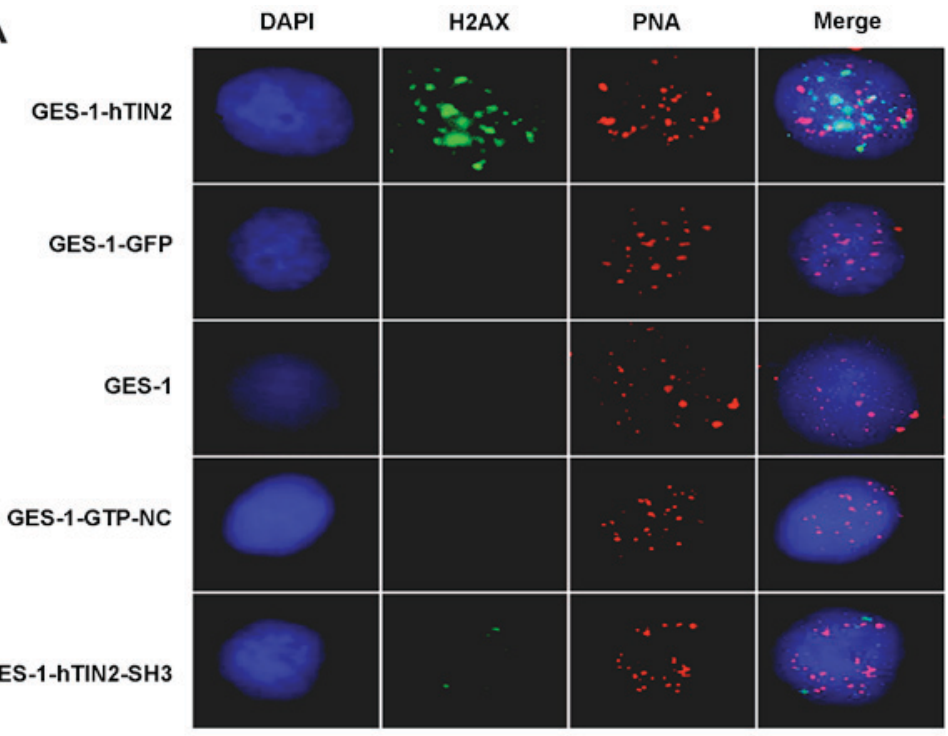

B

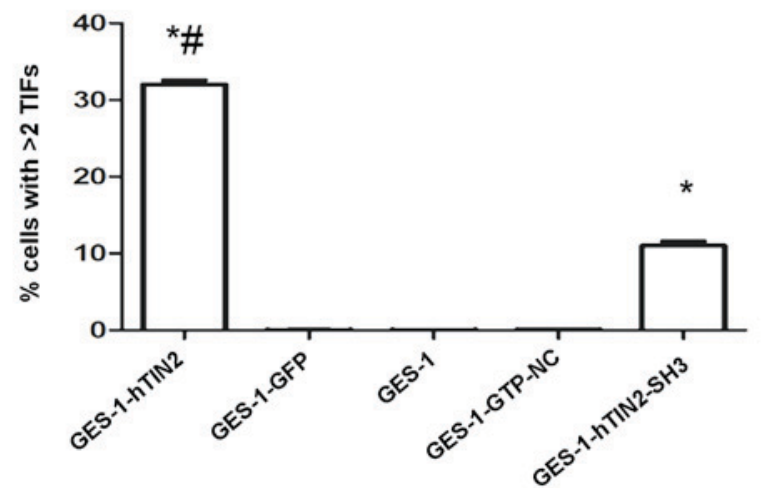

Figure 3. PNA-fluorescence in situ hybridization analysis of TIF formation. (A) Fluorescent staining of nuclei (blue), H2AX (green) and PNA (red). An increased number of TIFs were detected in the TIN2 high expression group compared with the group with inhibited TIN2 expression. TIFs were not detected in the other groups. (B) Percentage of cells with >2 TIFs in GES-1 and corresponding transfected cells lines. * P<0.05 vs. GES-1, GES-1-GFP and GES-1-GTP-NC. ${ }^{\#} \mathrm{P}<0.05$ vs. GES-1-hTIN2-SH3. Magnification, x1,000. GES-1, normal human gastric epithelial cell line; GES-1-GFP, TIN2 overexpression vector group; GES-1-hTIN2, TIN2 overexpression group; GES-1-GTP-NC, low TIN2 expression vector group; GES-1-hTIN2-SH3, inhibited TIN2 expression group; PNA, peptide nucleic acid; TIF, telomere dysfunction induced-foci; TIN2, TERF1-interacting nuclear factor 2.

\section{Results}

Levels of TIN2 expression as detected by RT-qPCR. GES-1 cell lines with overexpressed or inhibited TIN2 expression and their corresponding control cell lines were established. TIN2 gene expression was detected with GAPDH as the internal control. The level of TIN2 expression in normal GES-1 cells was set as 1 and acted as a control. As indicated in Fig. 1, the expression of TIN2 was higher in the GES-1-hTIN2 group and lower in the GES-1-hTIN2-SH3 group, compared with the level of TIN2 expression in normal GES-1 cells.

TIN2 protein expression in GES-1 cells with overexpressed or inhibited TIN2. Western blot analysis was performed with $\beta$-actin as the internal reference to evaluate TIN2 protein expression in GES-1 cells. The results from image analysis indicated high expression of TIN2 protein in the GES-1-hTIN2 group, compared with GES-1 cells $(\mathrm{P}<0.05$; Fig. 2). Additionally, low expression of TIN2 protein was detected in the GES-1-hTIN2-SH3 group compared with the GES-1 cells $(\mathrm{P}<0.05$; Fig. 2).
Detection of telomere dysfunction-induced damage by PNA-FISH analysis. The cells were observed under oil immersion for telomere dysfunction-induced damage. Green fluorescence signal indicated a positive $\mathrm{H} 2 \mathrm{AX}$ immunofluorescence signal, and red fluorescence indicated in situ hybridization signals. Yellow fluorescence indicated telomere signals, and the nuclei were counterstained with DAPI (blue). Overlapping green and red fluorescence indicated telomere dysfunction induced-foci (TIFs). As indicated in Fig. 3A, overlapping green and red fluorescent signals were detected in the high TIN2 expression group, whereas clear signal overlaps were not detected in other groups. A total of 500 cells were analyzed for each group. It was detected that one cell was positive for two TIFs. The positive (signal overlaps) rate for TIFs was $31 \%$ for the TIN2 overexpression group, $11 \%$ for the TIN2-knocked down group and $<1 \%$ for the other groups (Fig. 3B).

Chromosome analysis. The chromosome morphology of each cell line group was observed under oil immersion. The chromosomal aberrations of 100 cells per group 

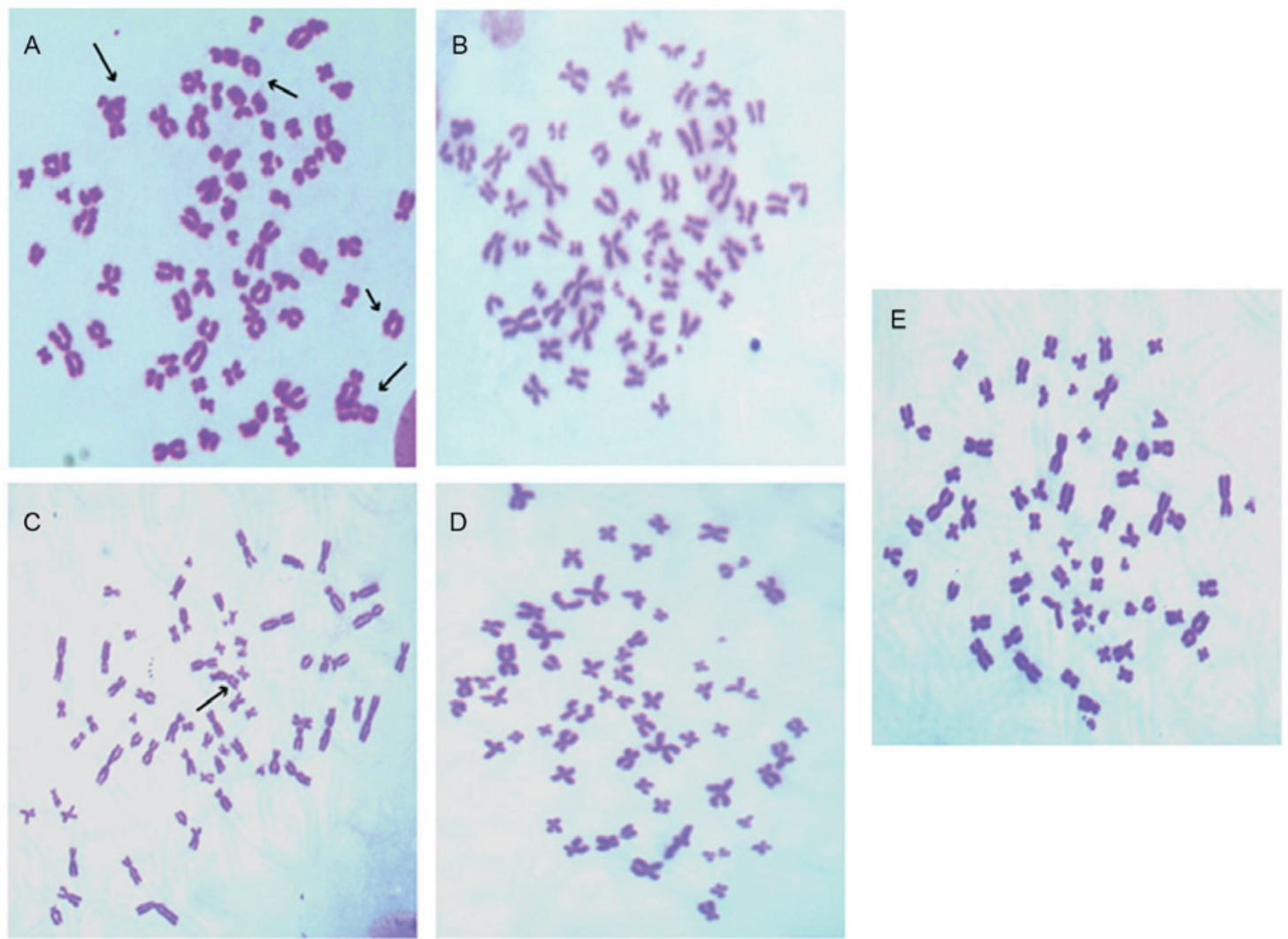

Figure 4. Chromosome morphology in (A) GES-1-hTIN2, (B) GES-1-GTP, (C) GES-1-hTIN2-SH3, (D) GES-1-GTP-NC and (E) GES-1 cells. The arrows indicate chromosomal aberrations. Chromosomal aberrations are detected in the GES-1-hTIN2 and GES-1-hTIN2-SH3 groups. Furthermore, the GES-1-hTIN2 group demonstrated more circular chromosome structures and chromosome end fusions, compared with the GES-1-hTIN2-SH3 group. Magnification, x1,000. GES-1-hTIN2, TIN2 overexpression group; GES-1-hTIN2-SH3, inhibited TIN2 expression group; GES-1-GTP-NC, low TIN2 expression vector group; GES-1-GFP, TIN2 overexpression vector group.

were recorded. As indicated in Fig. 4, circular chromosome structures and chromosome end fusions were detected in GES-1-hTIN2 chromosomes. Only $0.65 \pm 0.46$ per 100 cells chromosomal aberrations were detected in GES-1-hTIN2-SH3 chromosomes, whilst all other cell lines exhibited no chromosomal abnormalities. Statistical analysis was performed to compare the means of the treatment groups, and the data are presented in Table I. The comparisons were made between the GES-1-hTIN2 and GES-1-hTIN2-SH3 groups, and it was detected that the number of chromosomal aberrations significantly differed between these groups.

\section{Discussion}

The interaction between telomere DNA and shelterin is necessary to protect the ends of chromosomes because shelterin safeguards chromosomes (20). Chromosome end fusion occurs during chromosome breakage, thereby resulting in genomic instability, chromosome recombination, telomerase activation or upregulation and ultimately the development of malignant tumor (21). Telomere loss, breakage fusion bridge cycle and genome instability have been observed in the early stages of carcinogenesis in a model of melanoma cell malignancy (22). One previous study demonstrated that the knockdown of TRF1 and TIN2 genes resulted in alterations in telomere structure, thereby leading to chromosomal
Table I. Chromosomal aberration in each group.

\begin{tabular}{lc}
\hline Groups & Number of chromosomal aberration \\
\hline GES-1-hTIN2 & $2.48 \pm 1.30^{\mathrm{a}, \mathrm{b}}$ \\
GES-1-hTIN2-SH3 & $0.65 \pm 0.46^{\mathrm{a}}$ \\
GES-1 & 0 \\
GES-1-GFP & 0 \\
GES-1-GTP-NC & 0
\end{tabular}

aP $<0.05$ vs. GES-1, GES-1-GFP and GES-1-GTP-NC. ${ }^{\text {b}} \mathrm{P}<0.05$ vs. GES-1-hTIN2-SH3. GES-1-GTP-NC, low TIN2 expression vector group; GES-1-hTIN2-SH3, inhibited TIN2 expression group. NC, negative control.

aberrations (23). This series of processes is linked to the occurrence of malignant tumors in the blood system. In the present study, it was revealed that chromosomal aberrations were associated, not only with inhibited TIN2 expression but also with TIN2 overexpression. Notably, chromosomal aberrations associated with high TIN2 expression in GES-1 cells were more serious.

H2AX can be hallmarks of DNA damage sites. Telomere DNA damage can lead to the recruitment of H2AX, which results in the formation of TIFs (24). TIFs occur during the early stages of disease and carcinogenesis (25). In the present 
study, PNA-FISH was performed to investigate the causes of chromosome abnormalities including circular chromosome structures and chromosome end fusions. Compared with the GES-1 cells with inhibited TIN2 expression, there was an increased number of TIFs detected in the GES-1 cells overexpressing TIN2. The difference in the number of TIFs detected between the two groups was statistically significant.

In conclusion, abnormal TIN2 expression leads to damage in telomere DNA, which results in chromosomal aberrations. Compared with GES-1 cells with inhibited TIN2 expression, TIN2-overexpressing GES-1 cells exhibited greater marked telomere DNA damage and chromosomal aberrations. Shelterin negatively regulates telomeres (26), and consequently increased levels of shelterin correspond with increased telomere damage. TIN2 is a core part of the shelterin complex (27), which may account for why an increased number of TIFs was detected in GES-1 cells that overexpress TIN2 compared with GES-1 cells with inhibited TIN2 expression. TIN2 overexpression contributes a major role in telomere dysfunction. In the present study, it is concluded that telomere DNA damage is able to cause chromosomal aberrations. This process may be a contributory factor for the pathogenesis of gastric cancer.

In future studies, the aim is to further investigate the effect of TIN2 expression on TRF1, TRF2 and POT1 proteins in telomere-protective protein complexes. We further aim to investigate whether telomere dysfunction and chromosomal aberrations that are associated with high TIN2 expression are able to induce gastric cancer.

\section{Acknowledgements}

The present study was supported by the National Natural Science Foundation of China (grant no. 81401960).

\section{Competing interests}

The authors declare that they have no competing interests.

\section{References}

1. Bruedigam $\mathrm{C}$ and Lane SW: Telomerase in hematologic malignancies. Curr Opin Hematol 23: 346-353, 2016.

2. de Lange T: Shelterin: The protein complex that shapes and safeguards human telomeres. Genes Dev 19: 2100-2110, 2005.

3. O'Sullivan RJ and Karlseder J: Telomeres: Protecting chromosomes against genome instability. Nat Rev Mol Cell Biol 11: 171-181, 2010.

4. Frescas D and de Lange T: A TIN2 dyskeratosis congenita mutation causes telomerase-independent telomere shortening in mice. Genes Dev 28: 153-166, 2014.

5. Frescas D and de Lange T: Binding of TPP1 protein to TIN2 protein is required for POT1a,b protein-mediated telomere protection. J Biol Chem 289: 24180-24187, 2014.

6. Abreu E, Aritonovska E, Reichenbach P, Cristofari G, Culp B Terns RM, Lingner $\mathrm{J}$ and Terns MP: TIN2-tethered TPP1 recruits human telomerase to telomeres in vivo. Mol Cell Biol 30: 2971-2982, 2010.

7. Gramatges MM and Bertuch AA: Short telomeres: From dyskeratosis congenita to sporadic aplastic anemia and malignancy. Transl Res 162: 353-363, 2013.

8. Walne AJ, Vulliamy T, Beswick R, Kirwan M and Dokal I: TINF2 mutations result in very short telomeres: Analysis of a large cohort of patients with dyskeratosis congenita and related bone marrow failure syndromes. Blood 112: 3594-3600, 2008.
9. Bhanot M and Smith S: TIN2 stability is regulated by the E3 Ligase Siah2. Mol Cell Biol 32: 376-384, 2011.

10. Frescas D and de Lange T: TRF2-tethered TIN2 can mediated telomere protection by TPP1/POT1. Mol Cell Biol 34: 1349-1362, 2014.

11. Gancarcíková M, Zemanová Z, Brezinová J, Berková A, Vcelíková S, Smigová J and Michalová K: The role of telomeres and telomerase complex in haematological neoplasia: The length of telomeres as a marker of carcinogenesis and prognosis of disease. Prague Med Rep 111: 91-105, 2010.

12. Oh BK, Kim YJ, Park C and Park YN: Up-regulation of telomere-binding proteins, TRF1, TRF2, and TIN2 is related to telomere shortening during human multistep hepatocarcinogenesis. Am J Pathol 166: 73-80, 2005.

13. Kim H, Yoo JE, Cho JY, Oh BK, Yoon YS, Han HS, Lee HS, Jang JJ, Jeong SH, Kim JW and Park YN: Telomere length, TERT and shelterin complex proteins in hepatocellular carcinomas expressing 'stemness'-related markers. J Hepatol 59: 746-752, 2013.

14. Miyachi K, Fujita M, Tanaka N, Sasaki K and Sunagawa M: Correlation between telomerase activity and telomeric-repeat binding factors in gastric cancer. J Exp Clin Cancer Res 21: 269-275, 2002.

15. Klapper W, Krams M, Qian W, Janssen D and Parwaresch R: Telomerase activity in B-cell non-Hodgkin lymphomas is regulated by hTERT transcription and correlated with telomere-binding protein expression but uncoupled from proliferation. Br J Cancer 89: 713-719, 2003.

16. Saito K, Yagihashi A, Nasu S, Izawa Y, Nakamura M, Kobayashi D, Tsuji N and Watanabe N: Gene expression for suppressors of telomerase activity (telomeric-repeat binding factors) in breast cancer. Jpn J Cancer Res 93: 253-258, 2002.

17. Yamada M, Tsuji N, Nakamura M, Moriai R, Kobayashi D, Yagihashi A and Watanabe N: Down-regulation of TRF1, TRF2 and TIN2 genes is important to maintain telomeric DNA for gastric cancers. Anticancer Res 22: 3303-3307, 2002.

18. Hu H, Zhang Y, Zou M, Yang S and Liang XQ: Expression of TRF1, TRF2, TIN2, TERT, KU70, and BRCA1 proteins is associated with telomere shortening and may contribute to multistage carcinogenesis of gastric cancer. J Cancer Res Clin Oncol 136: 1407-1414, 2010.

19. Dai CH, Gan LN, Qin WU, Zi C, Zhu GQ, Wu SL and Bao WB: Use of fluorescence quantitative polymerase Chain reaction (PCR) for the dectetion of Escherichia coli adhesion to pig intestinal epithelial cells. Pol J Vet Sci 19: 619-625, 2016.

20. Kim SH, Davalos AR, Heo SJ, Rodier F, Zou Y, Beausejour C, Kaminker P, Yannone SM and Campisi J: Telomere dysfunction and cell survival: Roles for distinct TIN2-containing complexes. J Cell Biol 181: 447-460, 2008.

21. Shay JW: Role of telomeres and telomerase in aging and cancer. Cancer Discov 6: 584-593, 2016.

22. Silva AG, Graves HA, Guffei A, Ricca TI, Mortara RA, Jasiulionis MG and Mai S: Telomere-centromere-driven genomic instability contributes to karyotype evolution in a mouse model of melanoma. Neoplasia 12: 11-19, 2010.

23. Hartmann K, Illing A, Leithäuser F, Baisantry A, Quintanilla-Martinez L and Rudolph KL: Gene dosage reductions of Trf1 and/or Tin2 induce telomere DNA damage and lymphoma formation in aging mice. Leukemia 30: 749-753, 2016.

24. Zou L: Single- and double-stranded DNA: Building a trigger of ATR-mediated DNA damage response. Genes Dev 21: 879-885, 2007.

25. Augereau A, T'kint de Roodenbeke C, Simonet T, Bauwens S, Horard B, Callanan M, Leroux D, Jallades L, Salles G, Gilson E and Poncet D: Telomeric damage in early stage of chronic lymphocytic leukemia correlates with shelterin dysregulation. Blood 118: 1316-1322, 2011

26. Guièze R, Pages $M$, Véronèse $L$, Combes $P$, Lemal $R$, Gay-Bellile M, Chauvet M, Callanan M, Kwiatkowski F, Pereira B, et al: Telomere status in chronic lymphocytic leukemia with TP53 disruption. Oncotarget 7: 56976-56985, 2016.

27. Kim SH, Kaminker P and Campisi J: TIN2, a new regulator of telomere length in human cells. Nat Genet 23: 405-412, 1999. 